\title{
CÉSAR LATTES: UMA VIDA A SER CONTADA
}

\section{ARTIGO ORIGINAL}

LIMA, Gabriel Augusto Câmara Paiva ${ }^{1}$

SAPUNARU, Raquel Anna ${ }^{2}$

LIMA, Gabriel Augusto Câmara Paiva. SAPUNARU, Raquel Anna. César Lattes: Uma vida a ser contada. Revista Científica Multidisciplinar Núcleo do Conhecimento. Ano 05, Ed. 10, Vol. 05, pp. 181-196. Outubro de 2020. ISSN: 2448-0959, Link de acesso: https://www.nucleodoconhecimento.com.br/fisica/cesar-lattes

\section{RESUMO}

Este artigo relata um pouco da vida e da obra de um dos maiores físicos brasileiros, César Lattes. Muitos nomes importantes cruzaram o caminho de Lattes e junto com ele construíram a Física brasileira. Pode-se afirmar que sem a dedicação e o carisma desse notável cientista o ensino de física no Brasil não seria o mesmo. Sua dedicação à pesquisa repercutiram mundialmente, abrindo portas para o aprimoramento do ensino da física. Lattes possuía uma personalidade única, cativante e exuberante, mas às vezes conturbada. Por essas e muitas outras razões, sua vida e obra tem inspirado até os dias de hoje outros físicos, bem como professores, jornalistas e historiadores do mundo inteiro. O presente artigo é um relato histórico que poderá servir de apoio no ensino de física ou de ciências em geral. Trata-se de uma pesquisa bibliográfica.

Palavras-chave: Lattes, física, vida.

\footnotetext{
${ }^{1}$ Graduação em Ciência e Tecnologia.

${ }^{2}$ Orientadora. Doutorado em Filosofia. Mestrado em Filosofia. Graduação em Física.
} 


\section{INTRODUÇÃO}

Quem era César Lattes? Segundo o próprio (2001), o sobrenome Lattes, herdado do avô de seu pai é de origem judaica. Seu pai veio da Itália para Curitiba aos 19 anos, em 1912, para trabalhar no Banco Francês-Italiano. Em 1914, partiu de navio para lutar na $1^{\mathrm{a}}$. grande guerra ao lado dos austríacos e alemães. Foi durante esse período que seu pai conheceu sua mãe, uma professora de francês. Ao retornar em 1921, ele criou o Banco Brasul, no qual assumiu a gerência geral. Seu pai faleceu em 1975 e sua mãe em 1986. Lattes conta que eles o ajudaram muito, pois the deram um apartamento quando foi pai pela quarta vez, além de custear os tratamentos médicos de suas depressões.

Lattes nasceu em 1924, em Curitiba e aos dois anos mudou-se para Caxias do Sul. Depois foi para Porto Alegre, durante a Revolução de 1930. De Porto Alegre foi com a família para a Itália, onde ficou por seis meses e estudou numa escola pública em Turim. Voltando da Itália para Curitiba, lá permaneceu até 1933, quando aos nove anos, foi para São Paulo estudar no colégio interno Dante Alighieri. Casou-se, teve quatro filhas e nove netos, mas nenhuma delas seguiu o caminho da Física.

Cabe aqui explorar um pouco mais a motivação de Lattes para o estudo da Física. Este deveu-se a dois fatos: primeiro, ao terminar o ginásio, ele soube que um professor tinha três meses de férias por ano, ao invés de um mês, como ocorria com a maioria das demais profissões, o que o deixou bastante interessado e segundo, que a maioria das disciplinas eram do tipo "decoreba", à exceção de Física e de Matemática, das quais gostava e possuía facilidade. Assim, Lattes inclinou-se para o estudo da Física (BASSALO, 1990; MARQUES, 2005).

De acordo com Letícia Oliveira (2013), curiosamente descoberto pelos professores José Leite Lopes[3] e Gleb Vassielievich Wataghin[4] e possuidor das melhores notas do exame vestibular na Universidade de São Paulo, ninguém poderia imaginar a magnitude de tal feito quando Lattes aos seus 22 anos, sugeriu a Cecil Frank Powell[5] que acrescentasse boro as suas chapas fotográficas, utilizadas no estudo de emulsões nucleares. Isso o levou a ser indicado diversas vezes para o Prêmio Nobel 
de Física, título que não recebeu apenas porque na época era tradição que o prêmio fosse concedido aos chefes dos grupos de pesquisa, no caso, Powell.

Esses eventos mudaram o quadro da Física brasileira, pois o trabalho de Lattes mostrou que mesmo em um país menos desenvolvido onde o material para pesquisa não era tão abundante, era possível um jovem fazer uma descoberta mundialmente importante. A partir disso, os cientistas se animaram e criaram inúmeros institutos de pesquisa mesmo antes do retorno de Lattes para o país. Lattes tornou-se tão notável que recebeu várias homenagens e prêmios nacionais e internacionais. O maior deles em 1999, quando o CNPq o agraciou dando ao sistema de currículos acadêmicos o seu nome.

Posto isto, este artigo é objeto de uma breve estudo biográfico que se propôs a levantar e enaltecer alguns aspectos da vida de um dos mais brilhantes cientistas brasileiros, quiçá do mundo, o grande físico César Lattes. Assim, foi realizado um procedimento reflexivo e sistemático, no qual os dados foram obtidos por documentação indireta, isto é, pesquisa de uma bibliografia já existente, já que busca explicar e contar a vida desse pensador com base em contribuições teóricas publicadas em livros, artigos e sites institucionais. Trata-se, então, de um artigo de compilação, lembrando que esse tipo de estudo consiste em reunir ordenadamente a bibliografia selecionada, combiná-la e dela extrair aquilo que faz-se interessante para o cumprimento do objetivo. Em linhas gerais, foi feita uma pesquisa bibliográfica combinada com uma pesquisa histórica que abrange a leitura, a análise e a interpretação de livros, artigos e sites institucionais consagrados. Isso porque esse tipo de pesquisa tem por objetivo conhecer as diferentes contribuições disponíveis sobre determinado tema.

\section{VIDA E OBRA}

César Lattes não se considerava um físico, mas sim um professor, por isso dizia que "O físico acredita em uma realidade objetiva e o professor a ensina". (LATTES, 2001, p.18). Além disso, em relação à Física recente, proferia que os físicos apenas 
declaravam estar chegando ao fim da ciência e que não estamos nem no começo de tudo o que há para ser descoberto.

Para Lattes (2001), o maior físico brasileiro até então havia sido Marcelo Damy[6], pois não só teria descoberto coisas importantes, como também fabricou a aparelhagem, mediu e publicou os seus resultados, juntamente com Gleb Wataghin e Paulus "Pompéia" Aulus[7]. Particularmente sobre Wataghin, vale ressaltar que ele foi o pioneiro na Física Moderna do Brasil. Ele veio em missão do governo italiano quando Teodoro Ramos foi buscar professores na Europa para fundar a Faculdade de Filosofia, Ciências e Letras. A sua família era de origem russa e estava ligada a família real. Estava terminando Física em Kiev quando foi obrigado a se mudar para Turim por causa da revolução de 1917. Assim, embora grande parte dos físicos não saiba, eles são herdeiros de Wataghin.

Outras três personalidades muito importantes em sua opinião, foram Giuseppe Occhialini[8], envolvido com a descoberta da antimatéria de novas partículas, ponto de partida crucial para a exploração do universo através de raios $\mathrm{X}$ e raios gama $\mathrm{e}$ Joaquim Costa Ribeiro[9], descobridor da formação de dipolo de carga elétrica nas mudanças de fase dos sólidos e líquidos. Ele continuou seu relato afirmando que o fato de haver poucos nomes relevantes na Física não se devia ao fato de ser exigente em relação a isso, mas sim dos trabalhos possuírem mais nomes do que resultados. Isso tornava difícil dizer quem era bom, já que mesmo com o aumento no número de cientistas nessa área os grandes triunfos não surgiam.

Durante o seu curso de graduação, Lattes estudou Matemática e Física, além de outras disciplinas. Eram cerca de seis horas de aulas por dia, com aulas de laboratório que pegavam praticamente quase todo o seu dia, com os próprios alunos montando os experimentos. Em 1943, aos 19 anos, formou-se bacharel em Física e a partir daí todo o conhecimento que obteve foi através de estudos, tanto sozinho quanto com os colegas, além de ler revistas científicas. A biblioteca onde cursou sua graduação era belíssima e havia sido doada pelo governo italiano. Isto foi obra de Wataghin, que negociou com o governo italiano a doação de coleções completas de livros de Física e Matemática atualizados. Os salários eram bem melhores que os atuais. Quando se 
formou, Lattes conta: "Eu devia ganhar uns 900 por mês, o que devia dar, hoje, uns quatro mil dólares." (LATTES, 2001, p.28).

Logo no começo de sua carreira, Lattes foi convidado para ser o terceiro assistente da cadeira de Física Teórica e Matemática, regida por Wataghin. Realizou um trabalho em conjunto com Wathaghin sobre a abundância dos elementos no universo. Para tal, usou a termodinâmica estatística de altas densidades e temperaturas. Logo depois, foi convidado por Mário Schenberg[10] para calcular o campo de um dipolo puntiforme com momento angular. Após esse segundo trabalho, desistiu da Física Teórica e foi para a câmara de Wilson[11].

É importante saber que Occhialini e Wataghin não trabalhavam juntos. Wataghin era diretor do Departamento de Física e sempre deu maior crédito aos seus assistentes. Durante a II grande guerra, ele e sua esposa ficaram aqui. Considerado inimigo, não pode permanecer na chefia do departamento e ganhou uma sala com outra entrada, pois o departamento produzia sonares e outros equipamentos, todos voltados para a guerra. Agora Occhialini, inventou um controle automático e o colocou na câmara de Wilson. Foi com ele que fotografaram os pósitrons, em 1933. Porém, quem ganhou o Nobel foi o Wilson, em 1948. Em 1950, Powell ganhou o Nobel, mas, quando Lattes, Powell e Occhialini descobriram o méson-т, o Occhialini era mais conhecido, pelo seu trabalho de produção de pósitrons. Mesmo assim, deram o prêmio só para Powell. $\mathrm{Na}$ opinião de Lattes, Occhialini poderia ter ganhado um Nobel, mas prejudicaram-no duas vezes. Depois disso, ele foi para Bruxelas, depois Gênova, e, no final, foi para Milão coordenar a Física espacial italiana.

Mesmo Occhialini se tornando um administrador no final de sua carreira, Lattes o considerava um físico e não um professor; e mais: ele era um físico experimental, pois Lattes nunca o viu escrever uma única fórmula. Em seus trabalhos, Occhialini não entrava em detalhes teóricos. Como o mundo passava por guerras sucessivas, havia excesso de sobras de materiais de fácil acesso, como motores e outras coisas de interesse científico. Occhialini comprava muitas dessas peças para construir seus aparelhos e chegou a automatizar um microscópio. Lattes afirma que Occhialini "Era extremamente hábil. Teve um microscópio que ele fez, com motores controlados por 
pedais, para não ter de usar as mãos para mover as lâminas." (LATTES, 2001, p.36). Além disso ele tinha uma câmara de Wilson, mas não conseguia pô-la para funcionar. Lattes conseguiu. Contudo, foi ele quem ensinou a Lattes como operar essa câmara e inventou também um sistema automático de fixar emulsões. No entanto, logo embarcou para Bristol onde trabalharia com Powell.

Lattes, Ugo Camerini[12] e André Wataghin, filho de Wataghin, construíram sua própria câmara de Wilson, da qual tiraram fotografias que foram enviadas para Occhialini. Então, Occhialini mandou uma fotomicrografia que usava uma nova emulsão seis vezes mais concentrada, criada por ele. A emulsão que Powell usava era comum, na qual os riscos de prótons deveriam ser olhados com muito cuidado, pois havia muita interferência no fundo. Como Occhialini tinha dificuldade para ver esses riscos, com a nova emulsão o problema foi resolvido. Através da fotomicrografia, Lattes percebeu que com a câmara de Wilson, precisaria de duas mil vezes mais tempo para fazer a mesma coisa. Por essa razão, escreveu para Occhialini e pediu para que ele um lugar em Bristol. Powell e Occhialini arrumaram para ele uma bolsa da Wills, uma companhia de cigarros e a Fundação Getúlio Vargas pagou sua passagem de ida para Bristol.

Lattes relata que Powell não tinha iniciativa e que foi difícil tirá-lo de vinte anos de trabalho com emulsões fotográficas que poderiam ser adquiridas em lojas comuns. Ele foi o único aluno de Charles Thomson Rees Wilson[13], da câmara de Wilson, a fazer doutorado com ele. A emulsão fotográfica era barata, quase de graça, pois o laboratório estava colaborando com llford, empresa que fabricava as emulsões. Powell estava expondo chapas e ficou nisso, ou seja, trabalhando com espalhamento de nêutrons por vários alvos e espalhamento nêutron-próton. Após a reformulação das chapas o trabalho começou a apresentar resultados.

Vale ressaltar que essas chapas são sensíveis a luz visível, mas como o filme é concentrado e muito espesso, a luz visível cobria apenas a superfície e não conseguia penetrar. Mesmo se expostas a um pouco de luz, com álcool era possível tirar essa camada e o restante eram os grãos sensibilizados pelos prótons, além de alguns outros de fundo. Com chapas llford comuns, o tempo de exposição era de dois a três 
dias. Já essas chapas carregadas com bórax, podiam atingir até quinze. Com o decorrer do tempo, a imagem latente vai sumindo. Um próton de hoje e um próton de antes de ontem tinham uma densidade de grãos diferente e o bórax é que segurava a imagem latente. Dessa forma, Bristol bateu Cambridge, pois apenas Bristol possuía o bórax inventado por Lattes.

A descoberta do bórax ocorreu quando Lattes queria ver a desintegração do boro em duas partículas alfa e um $\mathrm{H}^{3}$ e pediu a llford que fizesse uma chapa contendo o próprio bórax. Depois, verificou-se que as chapas contendo bórax não tinham enfraquecimento da imagem latente. Como já dito, os filmes eram encomendados da Ilford e Bristol discutia sobre como melhorar a chapa, até o ponto em que era possível ver muito bem os prótons; e depois, em 1948, o elétron. As chapas eram de apenas uma emulsão, com duas a três polegadas de comprimento e recobertas com papel preto; empacotadas em luz vermelha e somente abertas após terminada a exposição, quando eram examinadas ao microscópio.

Como Occhialini e Powell estavam terminando o trabalho com as chapas antigas, coube a Lattes seguir o novo projeto. Quando Occhialini foi passar férias nos Pirineus, Lattes que estava interessado no boro, pediu a ele que levasse das chapas novas e antigas, para expô-las nas alturas. As que possuíam boro tiveram os melhores resultados. Assim, em uma chapa exposta nos Pirineus, foi possível detectar o primeiro decaimento . Então, Lattes dirigiu-se ao departamento de geografia e descobriu que na Bolívia, a $20 \mathrm{~km}$ de La Paz, existia um pico com um Clube Andino a $5.500 \mathrm{~m}$ de altura e acessível o ano todo. Ele sabia que a $5.500 \mathrm{~m}$ iria obter muito mais fenômenos que nos Pirineus, a 2.800 m. Com essa descoberta decidiu: "Vocês me pagam a viagem até o Brasil e eu me viro". (LATTES, 2001, p.46).

Lattes tomou um avião para o Brasil e em seguida um avião até La Paz. Chegando na Bolívia, foi ao Departamento de Física da Universidade de La Paz onde encontrou o professor Vicente Burgaleta, que o encaminhou até o diretor do Instituto de Meteorologia, Ismael Escobar. Lattes explicou a ele que queria expor as placas o mais alto possível durante um mês e então foram até o Clube Andino. Lá em cima, existe um pico em Chacaltaya. Lattes acreditava que quando Escobar construiu o 
observatório, não sabia da existência de um segundo cume. Assim, ele o construiu a $5.500 \mathrm{~m}$, no primeiro pico em Chacaltaya. Colocaram quatro placas de madeira formando uma pirâmide e duas outras acima. Lattes voltou para o Brasil, deixando as placas lá durante um mês e depois retornou para buscá-las.

Analisando a primeira placa juntamente com Guido Beck[14], no Rio, foi possível ver o terceiro méson-т. A primeira chapa havia sido revelada na casa de Escobar. A água não estava muito boa e ela ficou meio suja, mas mesmo assim foi possível ver o terceiro méson-m. Ele já havia encontrado dois, nas placas expostas nos Pirineus, mas em Chacaltaya ele tinha conseguido muito mais, cerca de trinta. A partir daí Lattes conseguiu estimar a massa de dois mésons. Quando publicou o trabalho com a avaliação da massa, mostrou que a desintegração do méson pesado saía um méson leve, hoje chamado de múon e algo leve e neutro que hoje se sabe, é o neutrino muônico.

Após isso, Niels Bohr[15] enviou assistentes para Bristol, para ficar a par da situação. Esses assistentes, contaram a Bohr que era Lattes quem estava fazendo as medidas. Lattes estava em Bristol e os assistentes de Bohr puderam vê-lo trabalhando. Logo depois, veio o convite para proferir seminários na Sociedade de Física Dinamarquesa, além de convites para discursar em Estocolmo e Lund. Bohr foi muito gentil com Lattes. Depois de apresentar dois seminários, ele o convidou para conversar no jardim interno de sua casa. Lattes Ihe contou sobre Chacaltaya e o motivo de sair de Bristol em uma época tão frutífera. Bohr então concordou e the disse: "mete a cara". (LATTES, 2001, p.50). Depois de seu pai, Bohr foi o homem que mais impressionou e inspirou Lattes, pela confiança que inspirava. Após isso, não houve mais contato entre eles.

É importante contextualizar o que acontecia no Brasil nesta mesma época em termos de estruturação para o desenvolvimento da ciência. Segundo Souza Barros (2013), em 1937, com a extinção da Universidade do Distrito Federal (UDF), foi criada a Universidade do Brasil (UB), onde foram agrupadas faculdades isoladas e escolas profissionais da antiga Universidade do Rio de Janeiro e da Universidade do Distrito Federal. A Faculdade Nacional de Filosofia (FNFi) foi fundada em 1939. Na década 
de 1940, quando foi criado o Centro Brasileiro de Pesquisas Físicas (CBPF) um conjunto significativo de seus fundadores, incluindo Lattes e Leite Lopes, eram professores da FNFi da UB. Em 1945, um decreto federal reformou a estrutura operacional da UB. A construção do campus da llha Universitária foi iniciada em 1945 no governo de Getúlio Vargas. Na época de Vargas, receitas extraordinárias foram destinadas pelo governo central para cobrir as despesas da transferência de faculdades e escolas profissionais para a llha Universitária. A transferência da Universidade do Brasil para a Ilha do Fundão, ato do governo de Getúlio Vargas, tinha o propósito de favorecer o crescimento de um centro universitário para contribuir no desenvolvimento do país.

Retornando aos acontecimentos físicos, em 1935, Hideki Yukawa[16] previu a existência do méson, mas Lattes e a equipe não estavam atrás dele. Em 1938, Carl David Anderson[17] e Seth Neddermeyer[18] detectaram o mésotron, que era o $\mu$ (múon), originado do $\pi$, sem interação forte. Existiam muitos grupos atrás desses mésons na época, mas o único método de detecção era através da chapa fotográfica e por isso havia uma turma de dez pessoas junto ao Powell. Quando já estava há mais ou menos um ano e meio em Bristol, Lattes foi para Berkeley, a fim de acompanhar de perto a produção artificial de mésons, pois isso o ajudaria em sua pesquisa, já que lá seria possível estudá-los com muito mais detalhes. Segundo Vieira e Videira:

[...] há um consenso entre os autores analisados neste trabalho que o resultado de maior repercussão para a física brasileira foram os obtidos por César Lattes em Bristol (Inglaterra) e em Berkeley (Estados Unidos). Em 1947, a equipe do Laboratório H. H. Wills, da Universidade de Bristol, da qual participava Lattes, detectou entre as partículas geradas pelo choque de raios cósmicos contra moléculas atmosféricas o chamado méson $\pi$ (ou píon), usando a técnica de emulsões nucleares (tipos especiais de fotografias empregadas na física nuclear). (2007, p.16).

Por trás da produção artificial do méson estava Milton Eugene Gardner[19], que juntamente com sua equipe, buscava o méson- $\mu$. No entanto, esse méson não pode ser produzido artificialmente, mas $0 \pi$ pode e este decai em $\mu$. Provavelmente eles não haviam tomado conhecimento sobre esse fato. Havia um eletroímã de quatro toneladas que estava sendo usado com calutron para separar isótopos de urânio de 
Hiroshima. Em 1946, no final da Guerra, ele foi levado para o laboratório em Berkeley de onde saiu o primeiro feixe contendo mésons, mas eles não conseguiam detectálos. Lattes e Gardner conseguiram produzir ambos os mésons somente em 1948, graças ao conhecimento a respeito do decaimento e a diminuição do papel preto em volta das emulsões.

\section{EVENTOS FINAIS}

1948 - A produção artificial de mésons causou muito mais alarme do que sua observação em raios cósmicos, pois permitiria trabalhar com eles em condições controladas, estabelecendo a abertura de um novo caminho para a Física Nuclear. Pelas descobertas, Lattes ganhou uma medalha Einstein da Academia Brasileira de Ciências, que doou para sua mulher. Lattes permaneceu em Berkeley por um ano, realizando vários seminários pela América do Norte, antes de seu retorno para o Brasil. Houve a oportunidade de permanecer nos Estados Unidos ao receber uma importante proposta de Harvard, que recusou. O fato é que sempre quis voltar ao Brasil para ajudar a melhorar o país. "Naquele tempo havia uma coisa esquisita que se chama patriotismo." (LATTES, 2001, p.56).

1949 - Quando retornou ao país, Lattes se encontrou com o General Dutra, que the disse que não seria uma boa ideia ficar por aqui, pois não dava para se desenvolver esses tipos de pesquisa. "Ele me pareceu uma pessoa honesta, bem-intencionada". (LATTES, 2001, p.58). O problema era que por causa de todo o custo de guerra e ainda Lattes sendo o assistente de Wataghin, a possibilidade de conseguir verbas era remota. Quando voltou, pediu demissão da USP e um mês depois saiu sua nomeação para catedrático interino de Física Nuclear e aplicada na Universidade Federal do Rio de Janeiro. Em 1951, fundaram o CBPF e Lattes foi eleito diretor científico, cargo que exerceu até 1955.

Fundação CBPF - Quando estava em Berkeley Lattes conheceu o auxiliar de consulado do Brasil em São Francisco, Nélson Lins de Barros, irmão de João Alberto de Lins Barros, que era ministro de primeira classe das Relações Exteriores na época. $\mathrm{Na}$ ocasião, Lattes pediu a Nélson para ajudá-lo na construção de um Centro de 
Pesquisas Físicas e quando Nélson retornou ao Brasil, levou Lattes ao encontro de seu irmão, que foi extremamente proativo para a construção. Lattes já havia retornado para os Estados Unidos quando João Alberto convocou uma assembleia para a fundação do centro, no qual foi feita uma ata e tudo começou em um escritório do próprio João Alberto, no Rio. Quando Lattes retornou, alugaram um andar na Rua Álvaro Alvim e algum tempo depois construíram um prédio e um galpão com a ajuda de Mário de Almeida, dono do Banco do Comércio, para o qual se mudaram. Posteriormente, Getúlio Vargas foi até Lattes e lhe perguntou como o centro funcionava e de que ele precisava e Lattes disse para ele a situação difícil em que o centro se encontrava. Foi a partir dessa conversa que que veio o dinheiro para que o centro funcionasse com tranquilidade. Sobre as atividades do centro, alguns cursos da faculdade eram dados por entendimento verbal e haviam seminários.

1954 e 1955 - Quando Enrico Fermi[20] faleceu, Lattes herdou o seu grupo em Chicago, do qual ficou encarregado por dois anos. Foi para lá quando recebeu um convite para que fosse trabalhar na Universidade de Chicago como pesquisadorassociado. Não os orientou, com exceção de Jerome Isaac Friedman, que posteriormente acabou ganhando um Nobel referente ao espalhamento inelástico de elétrons sobre prótons e sobre ligações de nêutrons que foram essenciais para o desenvolvimento do modelo dos quarks na Física de Partículas. Lattes conheceu Fermi quando ele visitou Berkeley, na época do méson-m. Depois disso, foi para Mineápolis onde novamente trabalhou com raios cósmicos, mas já estava com a depressão, que começou em 1955.

1956 - Quando retornou de Chicago, o convidaram para assumir a cadeira de Física superior em São Paulo, único lugar bem estruturado e com verbas na época. Lattes não estava bem de saúde, mas o único jeito de manter as filhas era com o salário de São Paulo. Em 1960, Marcelo Schein da Universidade de Chicago havia enviado para Lattes emulsões que havia exposto em balão a $30 \mathrm{~km}$ de altura. Daí ele ativou o grupo de emulsões da USP, realizando um trabalho com as mesmas e, em uma conferência internacional de raios cósmicos no Japão, em 1962, iniciou a colaboração BrasilJapão sobre raios cósmicos que perdura até hoje. 
Em 1964 foi para Pisa, onde exista um laboratório de Geologia Nuclear com muitos métodos de datação, interessado em estudar se as constantes da Física mudam em relação ao tempo. Enquanto esteve lá, colocou para funcionar um método de datação por fissão espontânea do urânio. Em 1965 quando retornou ao Brasil, o estado de sua depressão havia se agravado. Então Lattes decidiu que não poderia ficar mais entre o Rio e São Paulo. Damy que era o encarregado do Instituto de Física da Unicamp, escreveu um ofício para a USP e Lattes foi transferido para o Rio em setembro de 1967. Na Unicamp, trabalhou até 1986 quando se aposentou. Lá, o seu principal trabalho foi a colaboração Brasil-Japão e datação por fissão espontânea do urânio. Depois, aposentou-se pela UFRJ, em 1989 e em 1994 pegou a compulsória pelo CBPF.

Depois da aposentaria organizou um grupo em Cuiabá juntamente com Takao Tati, que normalizou a eletrodinâmica quântica, mas o grupo não permaneceu ativo por muito tempo. Lattes não se sentia satisfeito com o sistema educacional brasileiro, pois valorizava o ensino das ciências puras. Considerava o sistema estático demais e consequentemente retirava a criatividade dos jovens. Lattes como professor sempre procurava ensinar através das perguntas que realizava para as pessoas.

\section{CONCLUSÃO}

Através de artigos detalhados e metodologicamente bem feitos sobre expedições e observações astronômicas, nota-se que a História da Física estava bastante próxima da Astronomia durante o período colonial. As primeiras instituições científicas foram fundadas a partir de 1808, com chegada da Família Real. Foi em uma dessas instituições que se iniciaram as primeiras aulas práticas de Física no Rio de Janeiro, com o intuito de formar médicos e militares, objetivando resolver o problema da formação de mão-de-obra especializada na colônia. Logo em 1830, seguindo um padrão existente em países europeus, a Física ganharia sua autonomia como disciplina nos cursos médicos do Rio de Janeiro e também, posteriormente, como uma disciplina a ser ministrada nas academias militares e escolas profissionais. (VIEIRA; VIDEIRA, 2007). 
Em 1842, a Escola Militar no Rio de Janeiro iniciou o curso de Engenharia Civil e a partir daí passou a exigir a defesa de tese para o grau de doutor. Em 1848, Joaquim Gomes de Souza[21], conhecido como Souzinha, teria sido o primeiro a colar grau de doutor em uma instituição brasileira. Para Costa Ribeiro, Souzinha foi o primeiro físicomatemático brasileiro. Mesmo com o ensino de Física já consagrado no final do século XIX, a utilização de equipamentos de laboratório para pesquisa era pequena. A exceção residia nos poucos professores, oriundos de escolas politécnicas, que começaram a praticar as primeiras pesquisas através de iniciativa própria. (VIEIRA; VIDEIRA, 2007).

Luiz de Barros Freire[22], Doutor em Ciências Físicas e Matemáticas, foi um professor que mostrou-se preocupado com a formação de instituições científicas, sendo responsável pelo incentivo a físicos e matemáticos que se destacariam na ciência brasileira: Schenberg, Samuel MacDowell[23], Fernando de Souza Barros[24] e Leite Lopes. Freire foi diretor da UDF e na década de 1950, contribuiu para a criação do Instituto de Física e Matemática da atual Universidade Federal de Pernambuco. (VIEIRA; VIDEIRA, 2007).

O início da pesquisa sistemática em Física no Brasil ocorreu em 1934 com a criação da Faculdade de Filosofia, Ciências e Letras (FFCL) da Universidade de São Paulo, onde foram trazidos professores europeus para lecionar na instituição. Na ocasião, o ítalo-russo Wataghin veio para o Departamento de Física. Na instituição, Wataghin iniciou com jovens brasileiros, pesquisas áreas de raios cósmicos e Física Nuclear, tanto teóricas quanto experimentais. Em relação a outras faculdades brasileiras da época, a FFCL possuía alguns diferencias, sendo eles os salários condizentes, a dedicação integral à pesquisa e laboratórios equipados, que facilitaram os estudos por Wataghin e seus alunos. (VIEIRA; VIDEIRA, 2007).

Os primeiros resultados importantes começaram a ser obtidos após cinco anos desde o início da pesquisa em Física de forma sistematizada no Brasil. O primeiro trabalho foi o de Wataghin com seus alunos Damy e Pompéia. Eles apontaram que as interações com as partículas extremamente velozes, altamente energéticas, na forma de raios cósmicos, ao se chocarem com os átomos presentes na atmosfera da Terra, 
originariam muitas outras partículas menores numa formação em chuveiro. Seus resultados foram publicados, sendo citados por vários físicos que se dedicavam, tanto teórica quanto experimentalmente, ao estudo dos raios cósmicos. Todavia, a maior repercussão gerada para a Física brasileira foi através dos resultados obtidos por Lattes em Bristol e em Berkeley, com a detecção do chamado méson-m, gerado pelo choque de raios cósmicos contra moléculas atmosféricas. (VIEIRA; VIDEIRA, 2007).

A notícia foi amplamente noticiada no Brasil dias depois, influenciada por Leite Lopes, que utilizou o resultado de forma a impulsionar um projeto para criação de um centro de pesquisa em Física no Brasil. Esse foi um evento crucial para selar uma aliança entre a pequena comunidade de físicos da época juntamente com os militares e políticos, todos nacionalistas. Como não existia instituição com base sólida para a prática científica na época, foi criado então um centro privado: o CBPF, em 1949. Surgiriam também nos anos seguintes o CNPq, em 1951 e o Instituto de Matemática Pura e Aplicada (IMPA). Com o CNPq, um novo cenário foi formado, consolidando uma estabilidade para a pesquisa no Brasil. Houve a concessão de bolsas de estudo de aperfeiçoamento e doutorado, bolsas de auxílio para a contratação de pessoal técnico e compra de equipamentos e para a organização de cursos. (VIEIRA; VIDEIRA, 2007).

A partir disso, a nova tendência era a de se fazer Física de Partículas a partir de aceleradores, ideia que ganhou força a partir da segunda metade da década de 1950 nos Estados Unidos, impulsionada pelos resultados obtidos por Lattes e Gardner; e também no cíclotron de Berkeley. Desse modo, praticamente todos os dados relativos a partículas elementares passaram a ser fornecidos por aceleradores. (VIEIRA; VIDEIRA, 2007).

Terminado o panorama da Física brasileira, segue-se mais algumas curiosidades e informações relevantes para traçar-se o perfil de Lattes. Esse brilhante físico era membro de diversas associações entre as quais destacam-se a Academia Brasileira de Ciências, a União Internacional de Física Pura e Aplicada, o Conselho LatinoAmericano de Raios Cósmicos e as Sociedades Brasileira, Americana, Alemã, Italiana e Japonesa de Física. 
Lattes orgulhava-se particularmente das dezenas de municípios brasileiros que tiveram a iniciativa de conceder a suas escolas municipais, bibliotecas, praças e ruas o seu nome. Foi concedido a Lattes o título de cidadão honorário da Bolívia, em 1972, um reconhecimento pela sua atuação na América do Sul e pelo governo venezuelano, Ihe foi conferido um prêmio em 1977. Pela Organização dos Estados Americanos, Ihe foi conferido o prêmio Bernardo Houssay, em 1978. (BASSALO, 1990; MARQUES, 2005).

Durante todos os seus anos envolvido com o trabalho de pesquisa, Lattes preocupouse também com a formação altamente qualificada de seus alunos, fato comprovado pela série de Teses de Mestrado e Doutorado que orientou tanto no Brasil, quanto nos Estados Unidos e na Itália; tanto na área de emulsões nucleares quanto na área de geocronologia. Este perfil tornou Lattes o físico brasileiro mais conhecido no Brasil e ainda nos mostra porque recebeu as maiores honrarias de nosso país e do mundo durante sua vida. Até 1986, destacam-se o título de Doutor Honoris Causa outorgado pela USP, em 1948, e recebido somente em 1964; o título de "Cavaliere di Gran Croce", em 1948; Prêmio Einstein, da Academia Brasileira de Ciências, em 1951; a Medalha de Ouro "Honra ao Mérito", da Radio Nacional/ESSO, em 1951; o Prêmio Ciências, do Instituto Brasileiro de Educação, Ciência e Cultura, em 1953; o Prêmio Ernesto Fonseca Costa, do Conselho Nacional de Pesquisas, em 1953; o título de Cidadão Carioca, em 1957; o título de Cidadão Paulista Emérito, em 1958; o título de Personagem do Ano, pelo Grêmio cultural Rui Barbosa, em 1961; a Ordem do Mérito Cultural, da União Brasileira de Escritores, em 1969; o título de Cidadão Honorário de La Paz, Bolívia, em 1972; a Medalha Carneiro Felipe, do Conselho Nacional de Energia Nuclear, em 1973; o Prêmio Moinho Santista de Física, em 1975; a Comenda Andrés Bello, outorgada pelo Governador da Venezuela, em 1977; o Prêmio Bernardo Houssay, da Organização dos Estados Americanos, em 1978; os títulos de Doutor Honoris Causa e Professor Emérito, outorgado pela Unicamp, em 1987, porém ainda não recebidos e, em 1987, o Award in Physics of Third World Academy of Sciencies, em Trieste, Itália. (BASSALO, 1990; MARQUES, 2005). 
Finalizando, uma característica de Lattes que certamente era muito marcante, diz respeito à sua liberdade. Ele era um físico experimental que moldava o mundo das interações, esperando ainda que se conseguisse imaginar como trazer essas partículas à presença revelada. Sempre coerente, com dedicação enorme ao trabalho, Lattes era mobilizador do pensamento com ideias nem sempre aceitas ou compreendidas. Por exemplo, "As máquinas também têm vontade", disse em uma entrevista televisiva. (HAMBURGER, 2005).

Lattes foi um brilhante brasileiro que sempre soube buscar conhecimentos, meios e companheiros. Desbravou caminhos ainda obscuros da Física, descobrindo novos fenômenos que nos revelam a verdade sobre as configurações do universo. Seguiu um caminho louvável, dando continuidade às obras de Wataghin, Occhialini, Damy e Schenberg.

\section{REFERÊNCIAS}

ACADEMIA BRASILEIRA DE CIÊNCIAS. Samuel Wallace MacDowell. Disponível em: <http://www.abc.org.br/ smacdowell>. Acesso: 18 de dezembro de 2018.

BASSALO, J. M. F. César Lattes: Um dos Descobridores do Então Méson Pi. Cad. Cat. Ens. Fís., Florianópolis, 7(2): 133-148: ago. 1990.

FAPESP. Pioneiro da física ganha mostra. 23 de agosto de 2010. Disponível em: <http://agencia.fapesp.br/pioneiro_da_fisica_ganha_mostra/12667/>. Acesso: 5 de dezembro de 2018.

\section{GIFALLI, M. INSTITUTO DE ESTUDOS AVANÇADOS DA UNIVERSIDADE DE SÃO}

PAULO. 12/09/2014. Disponível em: <http://www.iea.usp.br/pessoas/pastapessoaf/fernando-de-souza-barros>. Acesso: 18 de dezembro de 2018.

HAMBURGER, A. I. LATTES, Físico Brasileiro. REVISTA USP, São Paulo, n.66, p. 132-138, junho/agosto 2005. 
LATTES, C. César Lattes: Descobrindo a Estrutura do Universo. Entrevistado por Jesus de Paula Assis. São Paulo UNESP, 2001.

MARCH. R. H. Ugo Camerini. Physics Today. 68, 7, 55 (2015). Disponível em: $<$ http://physicstoday.scitation.org/doi/full/10.1063/PT.3.2853>. Acesso: 12 de dezembro de 2018.

MARQUES, A. Reminiscências de César Lattes (Recollection from Cesar Lattes). Revista Brasileira de Ensino de Física, v. 27, n. 3, p. 467 - 482, (2005).

OLIVEIRA, L. Perfil César Lattes. IPEA. 2013. Ano 10 . Edição 78 16/01/2014.

RODITI, I. Dicionário Houaiss de Física. Rio de Janeiro: Objetiva, 2005.

SÓ BIOGRAFIAS. Guido Beck. Disponível em: <http://www.dec.ufcg.edu.br/biografias/GuidBeck.html>. Acesso: 19 de dezembro de 2018.

SOUZA BARROS, F. As passagens de Cesar Lattes e de Leite Lopes pela llha do Fundão: Notas e Discussões. Revista Brasileira de Ensino de Física, v. 35, n. 4, 4701 (2013).

THE WASHINGTON POST. SETH NEDDERMEYER, 80, DIES. February 2, 1988. Disponível em: <https://www.washingtonpost.com/archive/local/1988/02/02/sethneddermeyer-80-dies/95e11307-e574-487d-bebc-

6e6bbc2dfb7e/?utm_term=.7618ca66d69e>. Acesso: 21 de dezembro de 2018.

UNIVERSITY OF CALIFORNIA (SYSTEM) ACADEMIC SENATE. Milton E. Gardner, Physics: Davis. 1986, In Memoriam. Disponível em: $<$ http://texts.cdlib.org/view?docld=hb767nb3z6\&chunk.id=div00040\&brand=calispher e\&doc.view=entire_text>. Acesso: 21 de dezembro de 2018.

VIEIRA, C. L.; VIDEIRA, A. A. P. História e Historiografia da Física no Brasil. Revista de História e Estudos Culturais. Julho/Agosto/Setembro de 2007. Vol. 4. Ano IV. No. 13. 
Luiz Freire: Semeador de vocações científicas. Revista Brasileira de Ensino de Física. v. 35, n. 2, 2602 (2013).

\section{APÊNDICE - REFERÊNCIAS DE NOTA DE RODAPÉ}

3. "José Leite Lopes foi um físico brasileiro. Nasceu em Recife em 1918." (RODITI, 2005, p.139). Trabalhou em vários campos da Física entre os quais se destacam a Mecânica Quântica e a Teoria da Unificação das Forças.

4. Wataghin foi um físico russo naturalizado italiano. Como físico atuava igualmente bem na Física Teórica como na Física Experimental. Em sua homenagem, o Instituto de Física da UNICAMP recebeu o nome de Instituto de Física Gleb Wataghin. (RODITI, 2005).

5. Powell foi um físico britânico, ganhador do Prêmio Nobel de Física de 1950 pelo desenvolvimento do método fotográfico para estudar processos nucleares e pela descoberta do méson-p. (RODITI, 2005).

6. Marcello Damy de Sousa Santos foi o desenvolvedor de uma técnica que permitiu a descoberta dos chuveiros de raios cósmicos penetrantes, que trabalhou na fabricação do sonar brasileiro, desenvolveu o Betraton, a primeira máquina nuclear no Brasil e teve papel fundamental no desenvolvimento das pesquisas em Física no país. (BASSALO, 1990; MARQUES, 2005).

7. Paulus Aulus Pompéia foi um físico e também engenheiro brasileiro que participou de muitas experiências de detecção de raios cósmicos. Montou o Laboratório de Microscopia Eletrônica, uma técnica de análise pioneira e extremamente poderosa. Fez parte da Comissão de Organização do Centro Técnico da Aeronáutica (COCTA). Aposentou-se do ITA, em 1966, quando assumiu a cadeira de Física Aplicada na Faculdade de Arquitetura e Urbanismo da USP (FAU-USP). (BASSALO, 1990; MARQUES, 2005).

8. Occhialini foi um físico italiano foi um dos responsáveis por liderar na USP, na década de 1930, atividades pioneiras de pesquisa em Física no país, formando o 
primeiro grupo de estudantes na Faculdade de Filosofia e Letras, onde foi um dos fundadores do Departamento de Física, atual Instituto de Física. No Brasil, ajudou a formar os primeiros grupos de físicos brasileiros, tendo entre seus alunos Mário Schenberg e Cesar Lattes. Lattes o acompanhou na mudança para Bristol, onde se reuniram ao grupo de Cecil Frank Powell para descobrir a partícula subatômica méson-m. <http://agencia.fapesp.br/pioneiro_da_fisica_ganha_mostra/12667/>.

9. Joaquim Costa Ribeiro foi um físico e engenheiro civil e mecânico-eletricista brasileiro, realizou pesquisas experimentais sobre o comportamento de dielétricos associados a transições de fase, tendo descoberto o efeito termodielétrico ao investigar essas propriedades na passagem ao estado sólido da cera de carnaúba. Este efeito ficou conhecido como efeito Costa-Ribeiro e consiste no aparecimento de cargas elétricas quando certos dielétricos se solidificam. Por suas pesquisas, recebeu em 1946 o prêmio Einstein da Academia Brasileira de Ciências. (RODITI, 2005, p.54).

10. Mário Schenberg foi um físico brasileiro que se destacou principalmente pelo pioneirismo na Física Teórica e Matemática. Foi convidado por Occhialini para trabalhar como físico teórico do grupo de raios cósmicos na Universidade de Bruxelas, na Bélgica. No Brasil, assumiu cargo de diretor do Departamento de Física da Faculdade de Filosofia da USP. Sua gestão foi marcada pela criação de vários laboratórios, entre eles o Laboratório de Pesquisas em Estado Sólido e Baixas Temperaturas, hoje localizado na cidade universitária do campus de São Paulo, no prédio que leva seu nome. (BASSALO, 1990; MARQUES, 2005).

11. Câmara de condensação em que se obtém a supersaturação do vapor através de uma rápida expansão que produz um resfriamento adiabático e que serve para tornar visível a trajetória de partículas que, ao passarem pela câmera, formam gotículas. (RODITI, 2005, p.35).

12. Camerini foi um físico italiano que se uniu ao grupo de Powell no qual foram descobertos os mésons-T carregados, além de vários modos de decaimento dos mésons-K. <http://physicstoday.scitation.org/doi/full/10.1063/PT.3.2853>. 
13. Wilson foi um físico Britânico que ganhou o Nobel em 1927 pela invenção da câmara, que comprovou as previsões do efeito Compton e ficou conhecida como câmera de Wilson. Sua motivação original era o desenvolvimento de experiências que reproduzissem a formação de nuvens num laboratório. (RODITI, 2005, p.239).

14. Guido Beck foi um físico teórico austríaco, que realizou estudos que contribuíram para definir o modelo do núcleo atômico. Publicou pesquisas sobre o efeito Compton, a relatividade geral, ondas eletromagnéticas, efeito fotoelétrico, as consequências da analogia entre o quantum de luz e o elétron, o problema do atrito na mecânica quântica e a classificação dos isótopos, cujo trabalho sobre este último tema, contribuiu efetivamente para a aceitação pela comunidade científica dos conceitos que levaram ao modelo de camadas do núcleo atômico. $<$ http://www.dec.ufcg.edu.br/biografias/GuidBeck.html>.

15. Bohr foi um físico dinamarquês que em 1913 propôs um modelo quântico do átomo no qual supôs que o elétron estaria localizado em órbitas circulares bem definidas ao redor do núcleo e que a passagem de uma órbita para a outra se daria de modo descontínuo e com emissão ou absorção de uma quantidade de energia. Em 1922, ganhou o prêmio Nobel de Física por suas pesquisas sobre a estrutura dos átomos, assim como a radiação por eles emitida. (RODITI, 2005, p.27).

16. Yukawa foi um físico japonês, ganhou um Nobel de Física em 1949 por sua teoria de partículas elementares, na qual sugeriu a existência de uma força que mantinha prótons e nêutrons unidos no núcleo atômico. Em 1947, no trabalho com Cesar Lattes, é descrita a descoberta de uma partícula que se encaixava dentro das características previstas por Yukawa. (RODITI, 2005, p.242).

17. Anderson foi um físico norte-americano que em 1977 recebeu o Prêmio Nobel de Física por suas pesquisas sobre a estrutura eletrônica de sistemas magnéticos e desordenados. Seus vários trabalhos em Física da Matéria Condensada, tais como sobre propriedades de impurezas em sólidos, acoplamento de spins, superfluidez e supercondutividade possibilitaram avanços na eletrônica, principalmente na produção de computadores. (RODITI, 2005, p.11). 
18. Neddermeyer foi um físico norte-americano, codescobridor do múon. Por participar da descoberta do pósitron, por sua participação na descoberta do múon, a primeira das partículas subatômicas e por sua invenção da técnica de implosão para montagem de explosivos nucleares, recebeu em 1982 o Prêmio Enrico Fermi. $<$ https://www.washingtonpost.com/archive/local/1988/02/02/seth-neddermeyer-80dies/95e11307-e574-487d-bebc-6e6bbc2dfb7e/?utm_term=.7618ca66d69e> .

19. Gardner foi um físico norte-americano que durante a II grande guerra se juntou ao MIT Radiation Laboratory em Cambridge, Massachusetts, onde ajudou nesse gigantesco esforço para desenvolver e melhorar os sistemas de radar. Foi um excelente professor e passou inúmeras horas aperfeiçoando suas notas de aula e exames, aconselhando estudantes e preparando e construindo demonstrações de conferências.

$<$ http://texts.collib.org/view?docld=hb767nb3z6\&chunk.id=div00040\&brand=calispher e\&doc.view=entire_text>.

20. Enrico Fermi foi um físico nascido na Itália, naturalizado americano que ganhou o Prêmio Nobel de Física pela descoberta de novos elementos radioativos produzidos pela irradiação com nêutrons e pela indução de reações nucleares por nêutrons lentos. Descobriu também as leis estatísticas que regiam as partículas submetidas ao princípio de exclusão de Pauli; tais partículas passaram a ser chamadas de Férmions. (RODITI, 2005, p.92).

21. Joaquim Gomes de Sousa foi um Matemático, astrônomo, filósofo e parlamentar brasileiro. Foi pioneiro dos estudos matemáticos no Brasil. Com apenas dezenove anos de idade, obteve o grau de Doutor em Matemáticas e Doutor em Ciências Físicas e Naturais para os bacharéis egressos da instituição com a tese intitulada O Modo de Indagar Novos Astros sem Auxílio das Observações Directas em 1848, a partir das perturbações observadas no comportamento das órbitas de astros conhecidos, sem a utilização de observação direta. $<$ <ttp://www.dec.ufcg.edu.br/biografias/JoaGSouz.html>. 
22. Luís de Barros Freire foi um físico brasileiro, ingressou como professor na Escola de Engenharia de Pernambuco em 1921, onde se destacou por descobrir talentos entre jovens que moravam em Recife. Em 1933, tornou-se, por indicação do neurocientista Miguel Ozório de Almeida, membro correspondente da Academia Brasileira de Ciências (ABC). <http://www.scielo.br/pdf/rbef/v35n2/29.pdf>.

23. Samuel Wallace MacDowell é um físico e engenheiro brasileiro especializado em Física de Partículas que realiza pesquisas nas áreas de interações fracas e fortes, teorias de campos de Gauge, supersimetria e supergravidade. $<$ http://www.abc.org.br/ smacdowell>.

24. Fernando de Sousa Barros foi um físico e engenheiro brasileiro. Nascido em Recife em 1929, graduou-se em Engenharia Civil pela Universidade Federal de Pernambuco (UFPE) em 1952. Possui doutorado em Física Nuclear pela Universidade de Manchester (1960), na Inglaterra. Em 1964 foi contratado como pesquisador e, logo após, como professor pela Universidade Carnegie-Mellon, em Pittsburgh, nos Estados Unidos. Regressou ao Brasil na década de 1970 para implantar o Curso de PósGraduação em Física da Universidade Federal do Rio de Janeiro (UFRJ). Foi Professor Titular da UFRJ durante 26 anos, aposentando-se em 1999, e foi presidente da Sociedade Brasileira de Física de 1983 a 1985. < http://www.iea.usp.br/pessoas/pasta-pessoaf/fernando-de-souza-barros>. Faleceu em 8 de novembro de 2017.

Enviado: Agosto, 2020.

Aprovado: Outubro, 2020. 